\title{
Evaluation of Content Pertinence through Citation Count
}

\author{
Adeleke Victor Adedayo ${ }^{1,2 *}$ \\ ${ }^{1}$ Department of Materials Science and Engineering, Obafemi Awolowo University, Ile-Ife, ${ }^{2}$ Department of Metallurgical Engineering, \\ Kwara State Polytechnic, PMB 1375, Ilorin, Nigeria.
}

\section{INTRODUCTION}

In one of the online publications of Nature Publishing Group, Ball discussed issues relating to negative citation of science publications. ${ }^{[1]}$ He identified from the work of Alexander Oettl, an economist, at the Georgia Institute of Technology in Atlanta that the rate at which negative citations appear in the literature is low but not negligible. In the work of Alexander Oettl, the study team checked through citations in articles published in the Journal of Immunology. Immunologists helped the team to manually classifying "negative" citations. Overall, it was found that only about $2.4 \%$ of the citations were "negative." Although the paper concluded that the rate of the negative citation was low but not negligible, one may be tempted to conclude that the problem with citations analytics is a minor one. Unfortunately, this may not be the real situation because the significant amount of critiques on citation analytics indicates that the problem is not minor. While it has been argued severally that negative citations can adulterate citation analytics, it is also believed that the success of citation analysis methodologies relies on the integrity of the citing authors. The citation impact metrics would work better only if every citing author meticulously cited only the earlier works pertinent to the theme of the new manuscript. ${ }^{[2]}$ Therefore, pertinence of the cited reference to the new study being reported becomes crucial as an important consideration during performance evaluation. Actually, studies have been reported on analogy between citations and votes. In the studies, it was opined that by citing articles from a given journal in their own manuscripts, authors of academic writings are in essence casting votes for the primary literature. A count of these citations serves as a tally of those votes. However, it should be pointed out that votes are not always generally valid. Sometimes, votes can be invalid. ${ }^{[3]}$ One of the attributes that can determine validity of a citation is pertinence. Citation of an impertinent reference cannot count

*Address for correspondence:

E-mail: a.v.adedayo@gmail.com. as valid. Particularly, some citations made in the introduction/literature review sections may not qualify as pertinent and can be referred to as invalid votes.

\section{EVALUATION OF PERTINENCE}

One way to determine pertinence of citations in scientific articles is to classify all citations within the article. For article reporting empirical research, classification can be made into two, namely, (i) real citations and (ii) imaginary citations. Citations made in the methodology/results/ discussion of results/conclusions are classified as real citations because these truly show that the cited source support the new research being reported and thus is pertinent to the reported study. Citations made in the introduction/literature review sections are classified as imaginary citations. This because any citation made in the introduction/literature review that cannot be cited in the methodology/results/discussion of results/conclusions can only be stated to have imagined pertinence to the study. The pertinence is only a figment in the imagination of the citing author.

For example, by considering citations in the introduction sections of seventy randomly selected scientific articles, the total number of authors cited in the introduction sections were counted and recorded as $N_{\mathrm{e}}$. Further, a counting of common citations made both in the Introduction and any other section of the research article was made and recorded as $n_{c}$. Pertinence $(p)$ of each research article was determined by finding the ratio $n_{\mathrm{c}}: N_{\mathrm{c}}$ expressed as a percentage, i.e.,

$$
P=100\left(\frac{n_{c}}{N_{c}}\right)
$$

The overview of the variation of pertinence of the research articles analyzed [Figure 1] for the study showed that the entire articles studied have pertinence below $44 \%$. This means that the article with the highest pertinence 


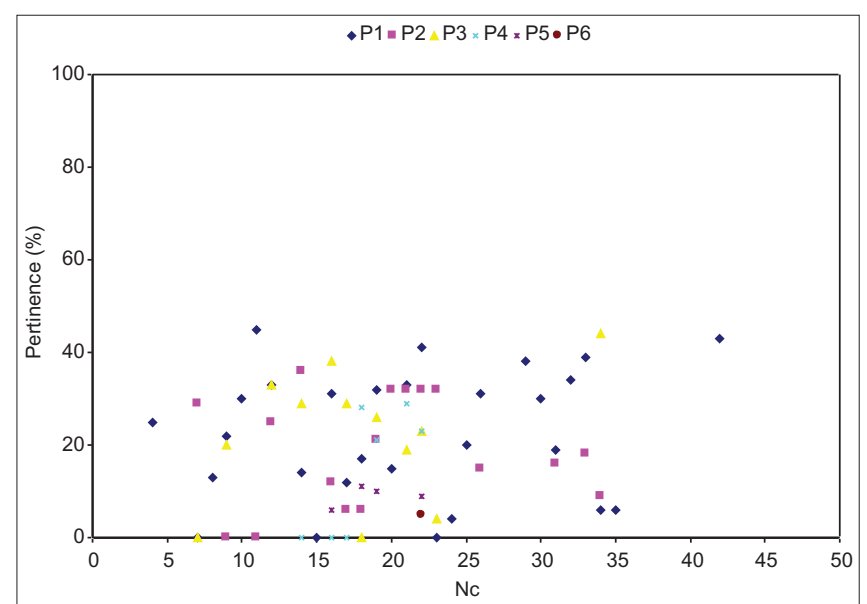

Figure 1: Overview of the variation of pertinence in research articles

This is an open access article distributed under the terms of the Creative Commons Attribution-NonCommercial-ShareAlike 3.0 License, which allows others to remix, tweak, and build upon the work non-commercially, as long as the author is credited and the new creations are licensed under the identical terms.

How to cite this article: Adedayo AV. Evaluation of content pertinence through citation count. J Scientometric Res. 2016;5(1):98-99.

Full text available at http://www.jscires.org/v5/i1 has about $56 \%$ citations that are not pertinent to the study! By all standards, this amount is significant.

\section{REFERENCES}

1. Ball P. Science Papers Rarely Cited in Negative Ways, Nature; 2015. Available from: http://www.nature.com/news/sciencepapers-rarely-cited-in-negative-ways-1.18643?WT.mc_id=FBK_ NA_1510_NEWSNEGATIVECITATIONS_PORTFOLIO. [Last accessed on 2015 Nov 17].

2. Cawkell AE. Science perceived through the Science Citation Index. Endeavour. 1977;1:57-62.

3. Adedayo AV. Pricing de Solla Price's circumvent. Adv Res. 2015;3:488-92.

\begin{tabular}{|c|c|}
\hline \multicolumn{2}{|c|}{ Access this article online } \\
\hline Official Publication of & \\
\hline & $\begin{array}{l}\text { Website: } \\
\text { www.jscires.org }\end{array}$ \\
\hline PhCc & $\begin{array}{l}\text { DOI: } \\
\text { 10.5530/jscires.5.1.15 }\end{array}$ \\
\hline
\end{tabular}

